\title{
Synthesis, Characterization, and Catalytic Activity of Pd(II) Salen-Functionalized Mesoporous Silica
}

\author{
Rotcharin Sawisai, Ratchaneekorn Wanchanthuek, \\ Widchaya Radchatawedchakoon, and Uthai Sakee \\ Creative Chemistry and Innovation Research Unit, Center of Excellence for Innovation in Chemistry (PERCH-CIC), \\ Department of Chemistry, Faculty of Science, Mahasarakham University, Mahasarakham 44150, Thailand
}

Correspondence should be addressed to Uthai Sakee; uthai.s@msu.ac.th

Received 15 March 2017; Revised 24 April 2017; Accepted 14 May 2017; Published 3 July 2017

Academic Editor: Bartolo Gabriele

Copyright (C) 2017 Rotcharin Sawisai et al. This is an open access article distributed under the Creative Commons Attribution License, which permits unrestricted use, distribution, and reproduction in any medium, provided the original work is properly cited.

\begin{abstract}
Salen ligand synthesized from 2-hydroxybenzaldehyde and 2-hydroxy-1-naphthaldehyde was used as a palladium chelating ligand for the immobilization of the catalytic site. Mesoporous silica supported palladium catalysts were prepared by immobilizing $\mathrm{Pd}(\mathrm{OAc})_{2}$ onto a mesoporous silica gel through the coordination of the imine-functionalized mesoporous silica gel. The prepared catalysts were characterized by X-ray diffraction (XRD), scanning electron microscopy (SEM), energy dispersive X-ray (EDX), inductivity couple plasma (ICP), nitrogen adsorption-desorption, and Fourier transform infrared (FT-IR) spectroscopy. The solid catalysts showed higher activity for the hydroamination of $C$-(tetra- $O$-acetyl- $\beta$-D-galactopyranosyl)allene with aromatic amines compared with the corresponding homogenous catalyst. The heterogeneous catalytic system can be easily recovered by simple filtration and reused for up to five cycles with no significant loss of catalytic activity.
\end{abstract}

\section{Introduction}

The synthesis of nitrogen containing compounds is of great importance in basic research and industrial processes due to these important structures playing vital roles in drug research and development $[1,2]$. Among the several methods to form $\mathrm{C}-\mathrm{N}$ bond from $\mathrm{N}-\mathrm{H}$ bond, hydroamination of unsaturated $\mathrm{C}=\mathrm{C}$ bonds has the benefit of being cost effective and feasible, and it is widely used by many researchers worldwide [3-7]. Allenes are a unique class of organic compounds with two cumulated double bonds [8]. There has been much interest in using them as starting material for the synthesis of allylamines. Only a small number of transition-metal catalyzed intermolecular hydroamination reactions of allenes have been described [9-14]. Previously, we reported the addition of amines to allene using $\mathrm{Pd}(\mathrm{OAc})_{2}$, from which a mixture of the desired allylic amine and a minor amount of dienic amine was obtained [15]. Following this, the gold catalytic hydroamination of allene was investigated to give the desired allylic amine with a moderate to good yield [16]. However, this reported method suffers from disadvantages, such as long reaction time, expensive catalyst, and unstable operating state. The practical application of the catalyst in liquid phase reactions is hindered by both high cost and difficulties in catalyst separation and recycling. The common catalysts for these reactions are generally homogeneous systems, which cause difficulties in recycling the catalyst and aggregation of metal nanoparticles [17]. Thus, a heterogeneous system for the metal catalyst is a reasonable step to avoid these problems, and it is feasible to overcome such limitations by employing Pd on a solid support [18]. When considering this, silica fulfils many of the required aspects as an appropriate solid support for the deposition of palladium catalysts [19, 20]. There have been several methods established towards the preparation of supported Pd-catalysts [21]. Silica, due to its inexpensive, comfortable, accessibility, high thermal resistant, high pore volume, and narrow pore size distribution characteristics, has been the focus of significant consideration 
compared to other operative supports like polymeric ionic liquid, alumina, MCM-41, SBA-15, and so on [22, 23]. Among the various N-based ligands, Schiff bases are well known as ligands for the complexation of metal ions and as catalysis because of their easy preparation and being simple and cost effective starting materials with high resistance under a variety of conditions. Therefore, many researchers have developed several approaches to immobilize palladium Schiff-base complexes on solid supports [24]. To date, only a few palladium(II) complexes attached to functionalized mesoporous silica supports have been synthesized and successfully applied in organic reactions. However, no catalytic study has focused on the hydroamination of allene using palladium supported on mesoporous materials as catalysts. In our ongoing efforts to develop greener organic reactions, we now report a simple strategy for the preparation and characterization of a novel Salen-functionalized mesoporous silica supported Pd Schiff-base complex as a reusable catalyst and its application for the hydroamination of $C$-(tetra- $O$-acetyl$\beta$-D-galactopyranosyl)allene (1) with aromatic amines.

\section{Experimental}

2.1. General. All the starting materials, reagents, solvents, and eluents were commercial and used as purchased without purification. Flash column chromatography was performed using a silica gel 60 (230-400 mesh). Allene (1) was prepared according to a previously described method $[25,26]$.

2.2. Material Characterization. The prepared catalyst was characterized by various techniques, such as SEM, SEM-EDX, XRD, FT-IR, and BET. XRD measurements were performed with a D8 Advance Bruker diffractometer with the $\mathrm{Cu}-\mathrm{K} \alpha_{1}$ and $\mathrm{Cu}-\mathrm{K} \alpha_{2}$ radiations over a wide $2 \theta$ range of $0^{\circ}-80^{\circ}$. Scanning electron micrographs (SEM) and energy dispersive $\mathrm{X}$-ray (EDX) analyses were operated on a JEOL JSM-6460LV microscope. The IR spectrum was obtained using a FT-IR spectrophotometer (Bruker, Tensor 27). The surface area and porosity were measured with a Quantachrome Autosorb 1MP. The palladium content was analyzed by an inductively coupled plasma optical emission spectrometer (ICP-OES, Optima 3000 DV, Perkin Elmer, EUA).

2.3. Catalyst Preparation. The catalyst was easily prepared from commercially available starting materials as shown in Scheme 1 .

2.3.1. General Procedure for Preparation of ImineFunctionalized Silica Gel (Salen-Silica): SiO ${ }_{2} @$ Imine. A commercially available silica gel (230-400 mesh) was dried by heating at $120^{\circ} \mathrm{C}$ for $12 \mathrm{~h}$ prior to use.

Method A. Salicylaldehyde or 3-hydroxy-2-naphthaldehyde (42.86 mol) and then 3-aminopropyltriethoxysilane (APTES) $(10 \mathrm{~mL}, 42.86 \mathrm{~mol})$ were added to toluene $(60 \mathrm{~mL})$. A yellowish color showed immediately due to the formation of the imine. The resulting solution was stirred at a refluxing temperature under a nitrogen atmosphere for $7 \mathrm{~h}$. After cooling, the solid silica gel $(20 \mathrm{~g})$ was added to the mixture and stirred at a refluxing temperature under a nitrogen atmosphere for $7 \mathrm{~h}$, and then the solids were filtered and washed thoroughly with toluene until the washings were colorless. The solid product was dried in air at $120^{\circ} \mathrm{C}$ overnight before being used in the next step, and the resulting materials were denoted as $\mathrm{SiO}_{2} @$ imineSA and $\mathrm{SiO}_{2} @$ imineNA for salicylaldehyde and 2-hydroxy-1-naphthaldehyde, respectively.

Method B. Silica gel ( $20 \mathrm{~g})$ was added to $60 \mathrm{~mL}$ of toluene. To this slurry, 42.86 mole of APTES was added and the resultant slurry was heated at $110^{\circ} \mathrm{C}$ under a nitrogen atmosphere for $7 \mathrm{~h}$, and then salicylaldehyde or 2-hydroxy-1-naphthaldehyde $(42.86 \mathrm{~mol})$ was added to the slurry and stirred at a refluxing temperature under a nitrogen atmosphere for $7 \mathrm{~h}$. Following this, the solids were filtered and washed thoroughly with toluene until the washings were colorless. The solid product was dried in air at $120^{\circ} \mathrm{C}$ overnight and denoted as $\mathrm{SiO}_{2} @$ imineSB and $\mathrm{SiO}_{2} @$ imineNB for salicylaldehyde and 2hydroxy-1-naphthaldehyde, respectively.

\subsubsection{General Procedure for Immobilization of $\mathrm{Pd}(\mathrm{OAc})_{2}$ onto Salen-Silica}

Method $I$. To a round-bottomed flask, palladium acetate $(415.68 \mathrm{mg}, 1.73 \mathrm{mmol})$ and acetone $(100 \mathrm{~mL})$ were added. The solution was stirred at room temperature for $30 \mathrm{~min}$ under a nitrogen atmosphere and then $5 \mathrm{~g}$ of $\mathrm{SiO}_{2} @$ imineSA was added. The mixture was stirred at room temperature for $24 \mathrm{~h}$. The deposited solids were filtered from the solvent and washed repeatedly through the Soxhlet extraction with ethanol and acetone until the washings were colorless, and they were dried overnight at $120^{\circ} \mathrm{C}$ and denoted as $\mathrm{SiO}_{2} @$ imineSA-Pd-I.

Method II. To a round-bottomed flask, palladium acetate ( $415.68 \mathrm{mg}, 1.73 \mathrm{mmol}$ ) and acetone $(100 \mathrm{~mL})$ were added. The solution was stirred at room temperature for $30 \mathrm{~min}$ under a nitrogen atmosphere and then $5 \mathrm{~g}$ of Salen-silica was added. The mixture was refluxed while being stirred for $4 \mathrm{~h}$. The deposited solids were separated from the solvent by filtration and washed repeatedly for Soxhlet extraction with ethanol and acetone, until the washings were colorless, and they were dried overnight at $120^{\circ} \mathrm{C}$ and denoted as $\mathrm{SiO}_{2} @$ imineSA-Pd-II, SiO ${ }_{2} @$ imineSB-Pd-II, SiO $2 @$ imineNA-PdII, and $\mathrm{SiO}_{2} @$ imineNB-Pd-II.

2.4. Procedure for Hydroamination of Allene (1). All reactions were run under an air atmosphere. A reaction tube was charged with allene (1) $(0.27 \mathrm{mmol})$, amine $(0.81 \mathrm{mmol}), \mathrm{Pd}$ catalyst ( $90 \mathrm{mg}, 5 \mathrm{~mol} \%$ ), trifluoroacetic acid (20 mol\%), and THF $(0.5 \mathrm{~mL})$. The reaction mixture was allowed to proceed while being stirred at room temperature. The progress of the reaction was monitored by TLC. After completion of the reaction, the catalyst was filtered off and the solvent was evaporated under reduced pressure, after which the residue was purified by flash column chromatography on silica gel to yield the product. The solid compounds were characterized by ${ }^{1} \mathrm{H}$ and ${ }^{13} \mathrm{C}$ NMR spectroscopy. 
<smiles>CCO[Si](CC)(OCC)OCC</smiles>

(a)<smiles>O=Cc1c(O)ccc2ccccc12</smiles>

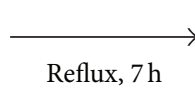<smiles>N=Cc1c(O)ccc2ccccc12</smiles>

(b)

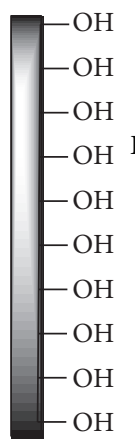

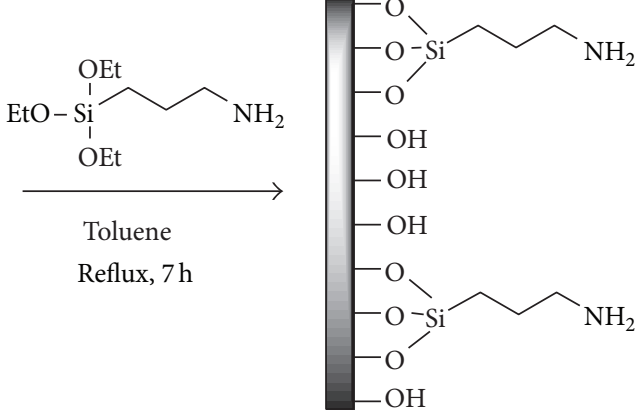<smiles>O=Cc1c(O)ccc2ccccc12</smiles>
Reflux, $7 \mathrm{~h}$

Silica

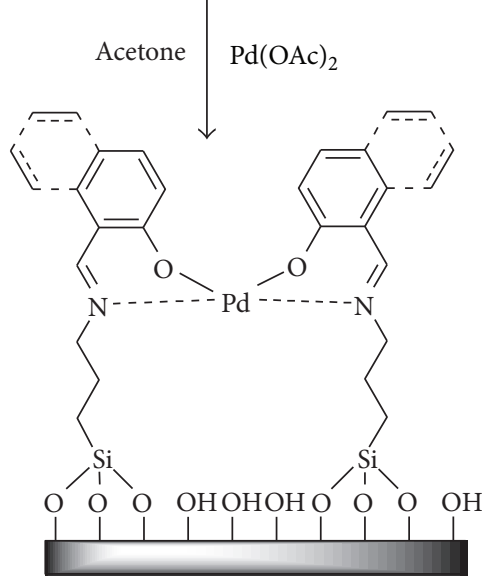

Scheme 1: Synthetic strategy for the preparation of the silica gel supported Pd catalyst. (a) Homogeneous route for mesoporous silica functionalization (method A) and (b) heterogeneous route for mesoporous silica functionalization (method B).

3a: ${ }^{1} \mathrm{H}-\mathrm{NMR}\left(400 \mathrm{MHz}, \mathrm{CDCl}_{3}\right): \delta 7.17(2 \mathrm{H}$, apt, $J 8.4$ and 7.2), $6.71(1 \mathrm{H}$, apt, $J 8.4$ and 7.2), $6.60(2 \mathrm{H}, \mathrm{d}, J$ 7.6), $5.98(1 \mathrm{H}$, $\mathrm{dt}, J 15.6$ and 5.2), $5.82(1 \mathrm{H}, \mathrm{q}, J 15.6$ and 5.2$), 5.37(1 \mathrm{H}, \mathrm{m})$, $5.28(1 \mathrm{H}, \mathrm{dd}, J 10.4$ and 6.0), $5.10(1 \mathrm{H}, \mathrm{dd}, J 10.4$ and 3.6), 4.81 $(1 \mathrm{H}$, apt, $J 6.0$ and 5.2), 4.00-4.16 $(3 \mathrm{H}, \mathrm{m}), 3.75-3.95(3 \mathrm{H}, \mathrm{m})$, $1.97-2.15(12 \mathrm{H}, 4 \times \mathrm{s}) ;{ }^{13} \mathrm{C}-\mathrm{NMR}\left(100 \mathrm{MHz}, \mathrm{CDCl}_{3}\right): \delta 170.52$, $170.19,170.06,169.87,147.64,134.47,129.27,123.49,117.87,113.14$, 72.53, 68.31, 68.29, 68.01, 61.83, 45.62, 20.73, 20.69, 20.66.

3b: ${ }^{1} \mathrm{H}-\mathrm{NMR}\left(400 \mathrm{MHz}, \mathrm{CDCl}_{3}\right): \delta 6.79(2 \mathrm{H}, \mathrm{d}, J 8.8)$, $6.60(2 \mathrm{H}, \mathrm{d}, J$ 8.8), $5.97(1 \mathrm{H}, \mathrm{dt}, J 15.6$ and 5.2$), 5.85(1 \mathrm{H}, \mathrm{q}$,
$J 15.6$ and 5.2), $5.37(1 \mathrm{H}, \mathrm{m}), 5.31(1 \mathrm{H}, \mathrm{dd}, J 10.4$ and 6.0$), 5.13$ (1H, dd, $J 10.4$ and 3.2), 4.81 (1H, apt, $J 6.0$ and 5.2), 4.00-4.15 $(3 \mathrm{H}, \mathrm{m}), 3.75-3.87(3 \mathrm{H}, \mathrm{m}), 3.74(3 \mathrm{H}, \mathrm{s}), 1.99-2.15(12 \mathrm{H}, 4 \times \mathrm{s})$; ${ }^{13} \mathrm{C}-\mathrm{NMR}\left(100 \mathrm{MHz}, \mathrm{CDCl}_{3}\right): \delta 170.53,170.23,170.13,170.08$, $152.44,141.82,134.79,123.41,114.92,114.57,72.50,68.40,68.33$, 68.04, 68.01, 61.87, 45.94, 20.72, 20.70, 20.66.

3c: ${ }^{1} \mathrm{H}-\mathrm{NMR}\left(400 \mathrm{MHz}, \mathrm{CDCl}_{3}\right): \delta 7.09(1 \mathrm{H}$, apt, $J 8.4$ and 8.0), 6.15-6.30 (3H, m), $5.99(1 \mathrm{H}, \mathrm{dt}, J 15.6$ and 5.2), $5.87(1 \mathrm{H}$, q, $J 15.6$ and 5.6), 5.38-5.40 $(1 \mathrm{H}, \mathrm{m}), 5.29(1 \mathrm{H}, \mathrm{dd}, J 10.4$ and 6.0), 5.11 (1H, dd, $J 10.4$ and 3.2), 4.80 (1H, apt, J 6.0 and 5.2), 
4.00-4.15 (4H, m), 3.82 (2H, d 5.2), 3.75 (3H, s), 1.96-2.16 $(12 \mathrm{H}, 4 \times \mathrm{s}) ;{ }^{13} \mathrm{C}-\mathrm{NMR}\left(100 \mathrm{MHz}, \mathrm{CDCl}_{3}\right): \delta 170.53,170.20$, $170.04,169.89,160.84,149.10,134.52,130.04,123.49,106.18$, $102.82,99.28,72.52,68.29,68.07,68.00,61.86,55.01,45.61$, $20.73,20.68,20.63$.

3d: ${ }^{1} \mathrm{H}-\mathrm{NMR}\left(400 \mathrm{MHz}, \mathrm{CDCl}_{3}\right): \delta 6.87(1 \mathrm{H}, \mathrm{dt}, J 7.6$ and 1.6), $6.78(1 \mathrm{H}, \mathrm{dd}, J 8.0$ and 1.2$), 6.69(1 \mathrm{H}, \mathrm{dt}, J 7.6$ and 1.2), $6.58(1 \mathrm{H}, \mathrm{dd}, J 8.0$ and 1.2), $6.02(1 \mathrm{H}, \mathrm{dt}, J 15.6$ and 5.2$)$, $5.87(1 \mathrm{H}, \mathrm{q}, J 15.6$ and 5.6), $5.37(1 \mathrm{H}, \mathrm{d}, J 3.2), 5.29(1 \mathrm{H}, \mathrm{dd}$, $J 10.4$ and 6.0), $5.12(1 \mathrm{H}$, dd, $J 10.4$ and 3.2$), 4.82(1 \mathrm{H}$, apt, $J$ 6.0 and 5.2), 4.00-4.16 $(3 \mathrm{H}, \mathrm{m}), 3.75-3.86(3 \mathrm{H}, \mathrm{m}), 3.85$ $(3 \mathrm{H}, \mathrm{s}), 1.98-2.13(12 \mathrm{H}, 4 \times \mathrm{s}) ;{ }^{13} \mathrm{C}-\mathrm{NMR}\left(100 \mathrm{MHz}, \mathrm{CDCl}_{3}\right)$ : $\delta 170.47,170.20,170.04,169.88,146.95,137.59,134.84,123.30$, $121.23,117.01,109.57,72.62,68.29,68.09,68.05,61.88,55.41$, 45.47, 20.75, 20.72, 20.68, 20.65.

3e: ${ }^{1} \mathrm{H}-\mathrm{NMR}\left(400 \mathrm{MHz}, \mathrm{CDCl}_{3}\right): \delta 6.99(2 \mathrm{H}, \mathrm{d}, J$ 8.4), $6.55(2 \mathrm{H}, \mathrm{d}, J$ 8.4), $6.00(1 \mathrm{H}, \mathrm{dt}, J 15.6$ and 5.2$), 5.86(1 \mathrm{H}, \mathrm{q}$, $J 15.6$ and 5.6), $5.37(1 \mathrm{H}, \mathrm{d}, J 3.2), 5.31(1 \mathrm{H}, \mathrm{dd}, J 10.4$ and 6.0), $5.11(1 \mathrm{H}, \mathrm{dd}, J 10.4$ and 3.6), $4.79(1 \mathrm{H}$, apt, $J 6.0$ and 5.6), 4.00-4.16 (4H, m), 3.82 (2H, d J 5.2), 2.22 (3H, s), 1.99-2.13 $(12 \mathrm{H}, 4 \times \mathrm{s}),{ }^{13} \mathrm{C}-\mathrm{NMR}\left(100 \mathrm{MHz}, \mathrm{CDCl}_{3}\right): \delta 170.50,170.19$, $170.04,169.86,145.37,134.73,129.76,127.09,123.34,113.35$, 72.59, 68.24, 68.05, 68.00, 61.83, 46.03, 20.70, 20.67, 20.34.

3f: ${ }^{1} \mathrm{H}-\mathrm{NMR}\left(400 \mathrm{MHz}, \mathrm{CDCl}_{3}\right): \delta 7.06(1 \mathrm{H}, \mathrm{t}, J 7.6), 6.55$ $(1 \mathrm{H}, \mathrm{d}, J \mathrm{7} .6), 6.38-6.48(2 \mathrm{H}, \mathrm{d}, \mathrm{m}), 6.01(1 \mathrm{H}, \mathrm{dt}, J 15.6$ and 5.2$)$, $5.87(1 \mathrm{H}, \mathrm{q}, J 15.6$ and 5.2), $5.39(1 \mathrm{H}, \mathrm{dd}, J 3.6$ and 1.6$), 5.31$ $(1 \mathrm{H}, \mathrm{dd}, J 10.4$ and 6.0$), 5.12(1 \mathrm{H}, \mathrm{dd}, J 10.4$ and 3.6$), 4.81(1 \mathrm{H}$, apt, J 6.0 and 5.2), 4.00-4.15 (4H, m), 3.84 (2H, d, J 5.2), 2.27 $(3 \mathrm{H}, \mathrm{s}), 1.97-2.14(12 \mathrm{H}, 4 \times \mathrm{s}) ;{ }^{13} \mathrm{C}-\mathrm{NMR}\left(100 \mathrm{MHz}, \mathrm{CDCl}_{3}\right)$ : $\delta 170.48,170.16,170.01,169.83,147.67,138.98,134.61,129.13$, $123.31,118.75,113.88,110.19,72.57,68.26,68.02,67.96,61.80$, 45.65, 21.54, 20.70, 20.65.

3g: ${ }^{1} \mathrm{H}-\mathrm{NMR}\left(400 \mathrm{MHz}, \mathrm{CDCl}_{3}\right): \delta 8.09(2 \mathrm{H}, \mathrm{d}, J$ 8.8), $6.58(2 \mathrm{H}, \mathrm{d}, J$ 8.8), $6.01(1 \mathrm{H}, \mathrm{dt}, J 15.6$ and 5.2$), 5.88(1 \mathrm{H}, \mathrm{q}$, $J 16.0$ and 5.2), 5.38-5.40 $(1 \mathrm{H}, \mathrm{m}), 5.30(1 \mathrm{H}, \mathrm{dd}, J 10.4$ and 5.6), $5.11(1 \mathrm{H}, \mathrm{dd}, J 10.4$ and 2.8), 4.82 (1H, apt, $J 6.0$ and 5.2), $3.75-4.18(6 \mathrm{H}, \mathrm{m}), 1.93-2.14(12 \mathrm{H}, 4 \times \mathrm{s}) ;{ }^{13} \mathrm{C} \mathrm{NMR}(100 \mathrm{MHz}$, $\left.\mathrm{CDCl}_{3}\right): \delta 170.64,170.17,170.08,169.77,152.98,138.32,132.15$, $126.36,124.85,111.39,72.24,68.45,68.23,67.95,67.82,61.73$, $44.89,20.73,20.69,20.64$.

3h: ${ }^{1} \mathrm{H}-\mathrm{NMR}\left(400 \mathrm{MHz}, \mathrm{CDCl}_{3}\right): \delta 7.55(1 \mathrm{H}, \mathrm{d}, J 8.0), 7.40$ $(1 \mathrm{H}, \mathrm{s}), 7.32(1 \mathrm{H}$, apt, $J 8.8$ and 8.0$), 6.90(1 \mathrm{H}, \mathrm{d}, J 8.0), 5.99(1 \mathrm{H}$, $\mathrm{dt}, J 15.6$ and 5.2), $5.92(1 \mathrm{H}, \mathrm{q}, J 15.6$ and 5.2), 5.37-5.40 $(1 \mathrm{H}$, $\mathrm{m}), 5.31(1 \mathrm{H}, \mathrm{dd}, J 10.4$ and 5.6$), 5.10(1 \mathrm{H}, \mathrm{dd}, J 10.4$ and 2.8$)$, $4.82(1 \mathrm{H}$, apt, $J 6.0$ and 5.2), 4.00-4.19 $(4 \mathrm{H}, \mathrm{m}), 3.93(2 \mathrm{H}, \mathrm{d}$, J 5.2), $1.96-2.17(12 \mathrm{H}, 4 \times \mathrm{s}) ;{ }^{13} \mathrm{C}-\mathrm{NMR}\left(100 \mathrm{MHz}, \mathrm{CDCl}_{3}\right)$ : $\delta 170.61,170.18,170.07,169.85,149.44,148.44,132.92,129.81$, $124.40,119.04,112.38,106.52,72.39,68.35,68.25,67.92,61.73$, 45.31, 20.72, 20.69, 20.66.

3i: ${ }^{1} \mathrm{H}-\mathrm{NMR}\left(400 \mathrm{MHz}, \mathrm{CDCl}_{3}\right): \delta 7.84(2 \mathrm{H}, \mathrm{d}, J$ 8.8), $6.59(2 \mathrm{H}, \mathrm{d} J$ 8.8), $5.97(1 \mathrm{H}, \mathrm{dt}, J 15.6$ and 5.2$), 5.85(1 \mathrm{H}$, q, $J 15.6$ and 5.2$), 5.35-5.40(1 \mathrm{H}, \mathrm{m}), 5.29(1 \mathrm{H}, \mathrm{dd}, J 10.4$ and 5.6), $5.10(1 \mathrm{H}, \mathrm{dd}, J 10.4$ and 3.2$), 4.81(1 \mathrm{H}$, apt, $J 6.0$ and 5.2), 4.0-4.17 (4H, m), $3.93(2 \mathrm{H}, \mathrm{d}, J 4.8), 2.50(3 \mathrm{H}, \mathrm{s})$, $1.96-2.16(12 \mathrm{H}, 4 \times \mathrm{s}) ;{ }^{13} \mathrm{C}-\mathrm{NMR}\left(100 \mathrm{MHz} \mathrm{CDCl}_{3}\right): \delta 196.43$, $170.53,170.15,170.03,169.78,151.74,133.05,130.78,130.73$, $127.01,124.12,111.73,111.66,72.32,68.35,67.92,67.85,61.74$, $44.83,25.98,20.70,20.65,20.60$.
2.5. Recycling Studies. Recycling studies were carried out using the procedure for the hydroamination of allene (1) $(0.27 \mathrm{mmol})$ with aniline $(0.81 \mathrm{mmol}), \mathrm{Pd}$ catalyst ( $\mathrm{SiO}_{2} @$ imineNB-Pd-II, $\left.90 \mathrm{mg}, 5 \mathrm{~mol} \%\right)$, trifluoroacetic acid $(20 \mathrm{~mol} \%)$, and THF $(0.5 \mathrm{~mL})$. After the reaction, the catalyst was separated from the reaction mixture by filtration through a sintered glass funnel. The separated catalyst was washed with dichloromethane $(3 \times 1 \mathrm{~mL})$, dried in a vacuum, and reused again to check its recycling efficiency.

\section{Results and Discussion}

3.1. Synthesis and Characterization of Catalyst. The preparation of the palladium immobilized on the Salen-silica is shown in Scheme 1. Salen was covalently bonded to the commercially available silica gel (230-400 mesh) giving the Salen-silica. It was readily prepared by two different approaches. The first route for the functionalized mesoporous silica used the homogenous system (method A) for the preparation of the silylating agent by the reaction of 3-aminopropyltriethoxysilane (APTES) with salicylaldehyde or 3-hydroxy-2-naphthaldehyde. The product was condensed with the silanol group of the solid silica gel to give the imine-functionalized silica gel (Scheme 1(a)). The solid powders from salicylaldehyde and 3-hydroxy-2-naphthaldehyde were designated as $\mathrm{SiO}_{2} @$ imineSA and $\mathrm{SiO}_{2} @$ imineNA, respectively. In the second route, the heterogeneous system (method B) involved the reaction of the silica gel with the APTES to give aminosilica followed by a condensation with salicylaldehyde or 3-hydroxy-2-naphthaldehyde to provide the Salen-silica (Scheme 1(b)). The solid powders from the reaction of salicylaldehyde and 3-hydroxy-2-naphthaldehyde were designated as $\mathrm{SiO}_{2} @$ imineSB and $\mathrm{SiO}_{2} @$ imineNB, respectively. Finally, the precursor $\mathrm{SiO}_{2} @$ imineSA was applied for the synthesis of the Pd complex by reacting with $\mathrm{Pd}(\mathrm{OAc})_{2}$ in acetone at room temperature for $24 \mathrm{~h}$ (method I) to give the product, designated as $\mathrm{SiO}_{2} @$ imineSA-PdI. The Pd complexes of $\mathrm{SiO}_{2} @$ imineSA, $\mathrm{SiO}_{2} @$ imineSB, $\mathrm{SiO}_{2} @$ imineNA, and $\mathrm{SiO}_{2} @$ imineNB were also obtained by reacting with $\mathrm{Pd}(\mathrm{OAc})_{2}$ in acetone under reflux conditions for $4 \mathrm{~h}$ (method II) to provide the resulting products, and they were designated as $\mathrm{SiO}_{2} @$ imineSA-Pd-II, $\mathrm{SiO}_{2} @$ imineSBPd-II, SiO $\mathrm{S}_{2} @$ imineNA-Pd-II, and $\mathrm{SiO}_{2} @$ imineNB-Pd-II, respectively. The characterization of the $\mathrm{SiO}_{2} @$ imine and Salen-silica supported Pd complex were done on the basis of their properties, such as via FT-IR, XRD, SEM, SEM-EDX, ICP-OES, and $\mathrm{N}_{2}$ adsorption-desorption spectra data.

The silanol $(\equiv \mathrm{Si}-\mathrm{OH})$ groups on the surface of the silica showed a significant qualification through silylation. Figure 1 shows the FT-IR spectra of (I) $\mathrm{SiO}_{2}$, (II) $\mathrm{SiO}_{2} @$ imineSA, (III) $\mathrm{SiO}_{2} @$ imineSB, (IV) $\mathrm{SiO}_{2} @$ imineSA-Pd-II, (V) $\mathrm{SiO}_{2} @$ imineSB-Pd-II, and (VI) $\mathrm{SiO}_{2} @$ imineSA-Pd-II. According to Figure 1, the characteristic silica bands combined with a silica backbone can be clearly detected in all spectra. The characteristic Si-O-Si bands at 1057 and $799 \mathrm{~cm}^{-1}$, present in all samples, are assigned to the silica network. The spectrum of the free silica displays a typical broad band at $3361 \mathrm{~cm}^{-1}$ due to the vibration of the $\mathrm{H}$ bond of the silanol 


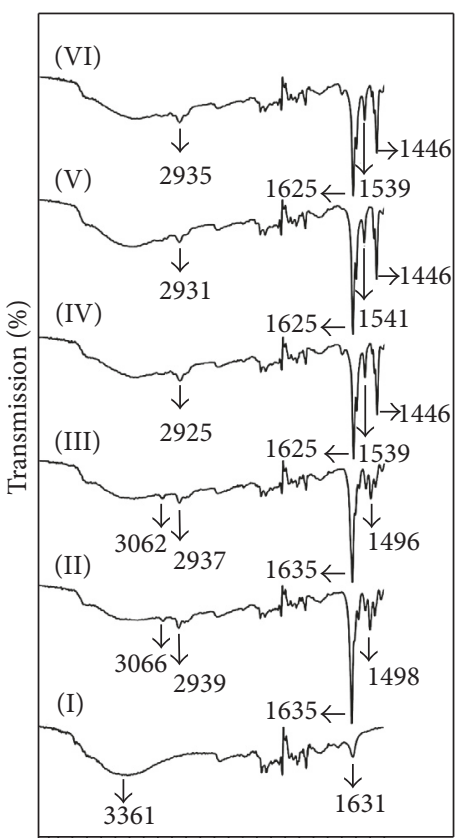

390034002900240019001400 Wavelength $\left(\mathrm{cm}^{-1}\right)$

(a)
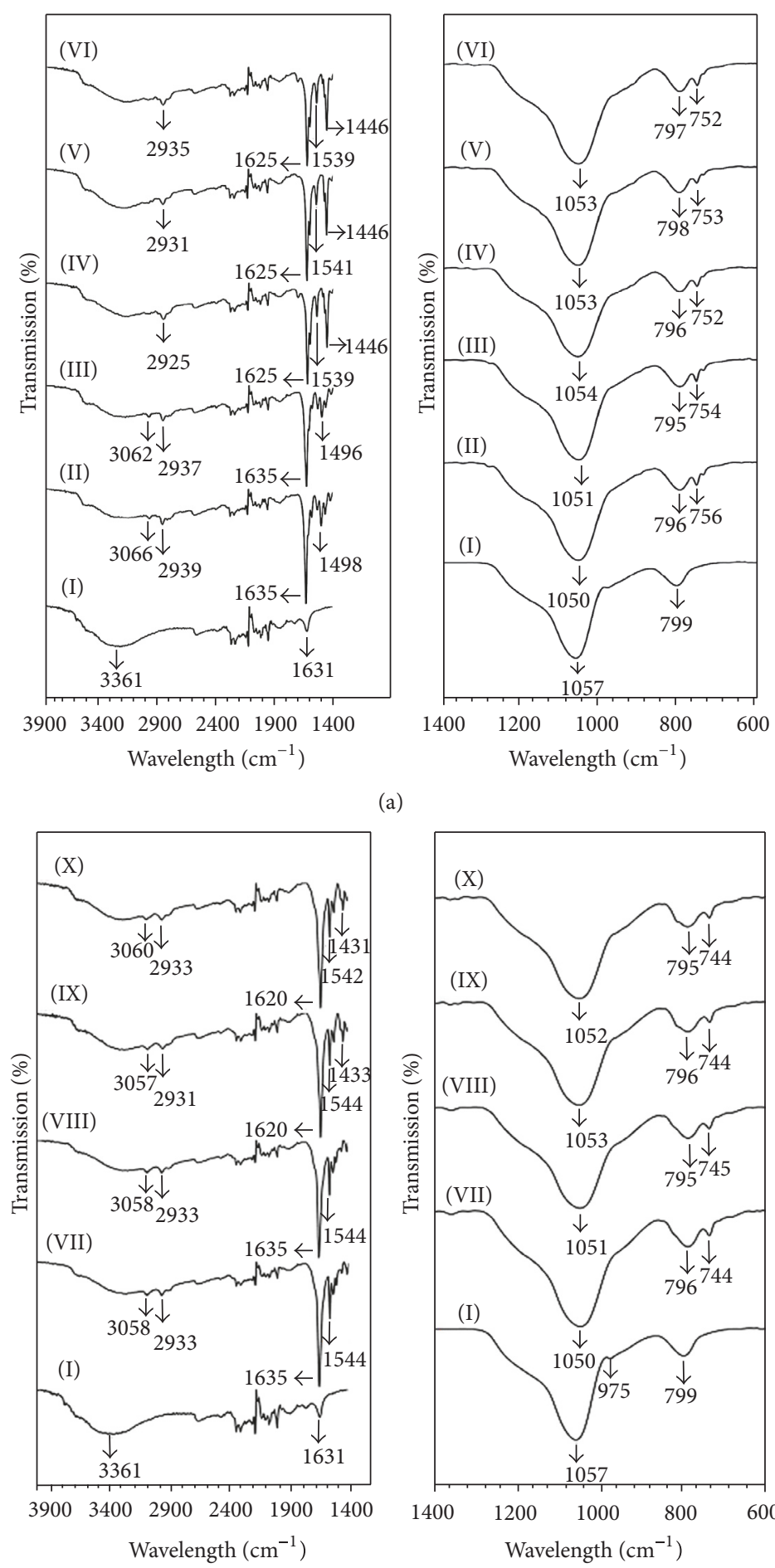

(b)

Figure 1: (a) FT-IR of (I) $\mathrm{SiO}_{2}$, (II) $\mathrm{SiO}_{2} @$ imineSA, (III) $\mathrm{SiO}_{2} @$ imineSB, (IV) $\mathrm{SiO}_{2} @$ imineSA-Pd-II, (V) SiO $\mathrm{S}_{2} @$ imineSB-Pd-II, and (VI) $\mathrm{SiO}_{2} @$ imineSA-Pd-II. (b) FT-IR of (I) $\mathrm{SiO}_{2}$, (VII) $\mathrm{SiO}_{2} @$ imineNA, (VIII) $\mathrm{SiO}_{2} @$ imineNB, (IX) SiO $@$ @ imineNA-Pd-II, and (X) SiO $@$ imineNB-Pd-II. 


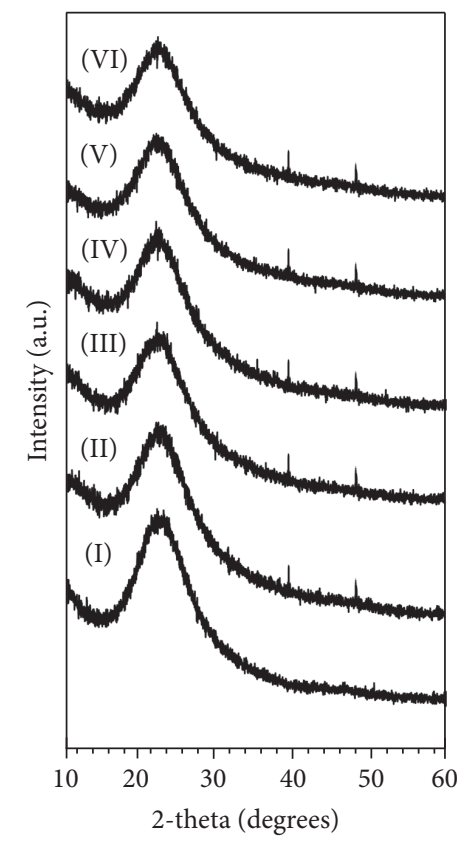

Figure 2: XRD patterns of (I) $\mathrm{SiO}_{2}$, (II) $\mathrm{SiO}_{2} @$ imineSA, (III) $\mathrm{SiO}_{2} @$ imineSB, (IV) $\mathrm{SiO}_{2} @$ imineSA-Pd-II, (V) SiO $2 @$ imineSB-Pd-II, and (VI) $\mathrm{SiO}_{2} @$ imineSA-Pd-II.

group and water of the siloxane backbone. The spectra of all the samples (Figures 1(a) and 1(b)) of the modified silica were identified by the presence of two weak bands at $3058-3066$ and $2931-2939 \mathrm{~cm}^{-1}$ due to the vibration of the aromatic and aliphatic $\mathrm{C}-\mathrm{H}$ groups, respectively. Meanwhile, the bending vibration of the $\mathrm{Si}-\mathrm{OH}$ on the free silica at $975 \mathrm{~cm}^{-1}$ significantly decreased after grafting with APTES. The Schiff bases display strong bands at 1635 and $1498 \mathrm{~cm}^{-1}$ due to the azomethine $(\mathrm{C}=\mathrm{N})$ and phenolic $(\mathrm{C}-\mathrm{O})$ stretching modes, respectively. The band at $1635 \mathrm{~cm}^{-1}$, upon the reaction of the Salen complex with $\mathrm{Pd}$, shifted to a lower frequency (1625 $\mathrm{cm}^{-1}$ for $\mathrm{SiO}_{2} @$ imineSA-Pd and $\mathrm{SiO}_{2} @$ imineSB-Pd; $1625 \mathrm{~cm}^{-1}$ for $\mathrm{SiO}_{2} @$ imineNA-Pd and $\mathrm{SiO}_{2} @$ imineNB-Pd), which indicated the formation of a Pd complex. The powder X-ray diffraction patterns of the parent silica gel $\left(\mathrm{SiO}_{2}\right)$ and palladium immobilized Salen-silica are shown in Figure 2.

The patterns have a broad peak of $2 \theta=22.4^{\circ}$, which indicated that the material had low crystallinity or the amorphous nature of the silica. A few decreases in the intensity were identified for the Pd(II)-Salen-silica that confirmed the immobilization of the Salen-silica. This decrease in intensity could be due to the covering of the pores in the silica surface during the metalation.

In good agreement with the XRD, the SEM images of the free silica and supported $\mathrm{Pd}(\mathrm{II})-\mathrm{Schiff}$-base@SiO $\mathrm{S}_{2}$ samples (Figure 3) showed the ordered channel structure of the mesoporous materials, which is stored during the complex grafting. The silica gel did not change significantly in size or gathered state under the supported processes in method II, but the presence of palladium caused a significant decrease in the silica particle size from the preparation with method I. Although the palladium particles and their dispersions are not clearly visible from the SEM spectra, considering the results of the SEM-EDX (Figure 4) and the ICP-OES, it was possible to define the palladium attachment on the surface of the silica supports. The presence of palladium in the $\mathrm{Pd}(\mathrm{II})-\mathrm{Schiff}-$ base@SiO${ }_{2}$ samples could be clearly seen from Figure 4 . The amount of adhered palladium was evaluated by ICP-OES, as shown in Table 1.

The results from the $\mathrm{N}_{2}$ adsorption-desorption isotherms of the silica-based samples and the respective textural parameters containing the specific surface area (SBET), the pore diameter, and the total pore volume $\left(V_{\text {total }}\right)$ are summarized in Table 1. The isotherms of all samples showed typical type IV patterns corresponding to the IUPAC definitions of porosity (Figure 5). The specific surface area provided by the BET method for the free $\mathrm{SiO}_{2}$ was $411.16 \mathrm{~m}^{2} \mathrm{~g}^{-1}$, which upon functionalization by methods $\mathrm{A}$ and $\mathrm{B}$ with salicylaldehyde and 3-hydroxy-2-naphthaldehyde gave $\mathrm{SiO}_{2} @$ imineSA, $\mathrm{SiO}_{2} @$ imineSB, $\mathrm{SiO}_{2} @$ imineNA, and $\mathrm{SiO}_{2} @$ imineNB, which were reduced to $340.58,366.92,273.49$, and $268.89 \mathrm{~m}^{2} \mathrm{~g}^{-1}$, respectively. In addition, the nitrogen adsorption-desorption studies indicated that a significant decrease in pore size by the imine-functionalization of the silica channels was monitored. There was not much difference in the surface areas of the various catalysts (entries 6-10, Table 1), with values between ca. 302 and $358 \mathrm{~m}^{2} \mathrm{~g}^{-1}$. Different surface areas and pore volumes can support different activities of the porous solid catalysts, but there was no support due to different pore volumes and BET surface areas in this study. 


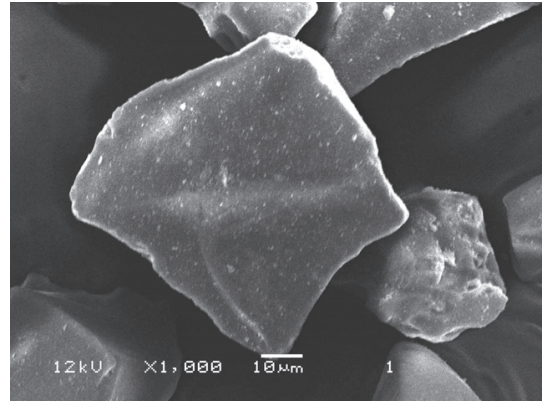

(a)

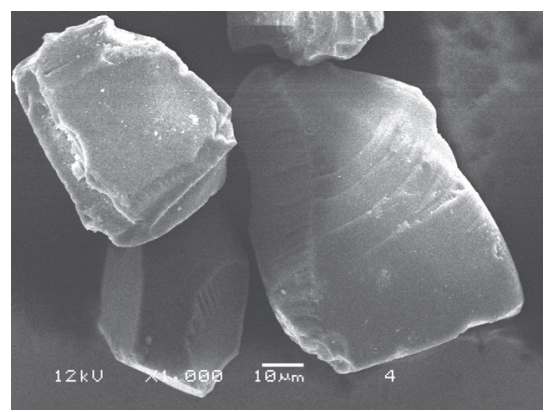

(d)

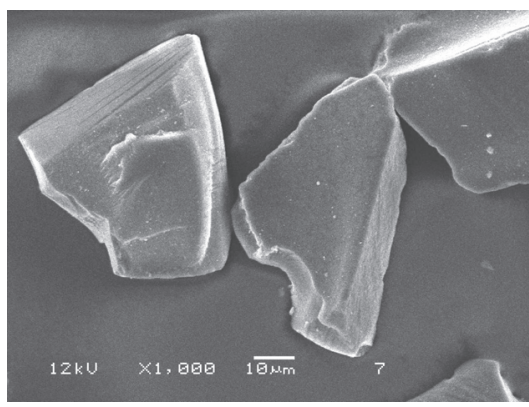

(g)

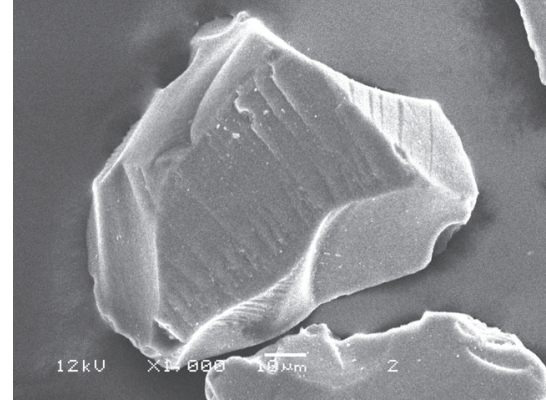

(b)

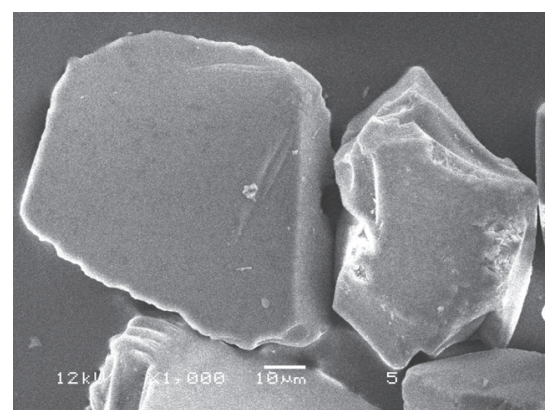

(e)

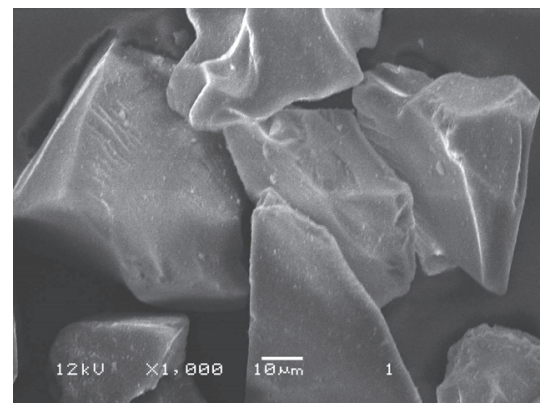

(h)

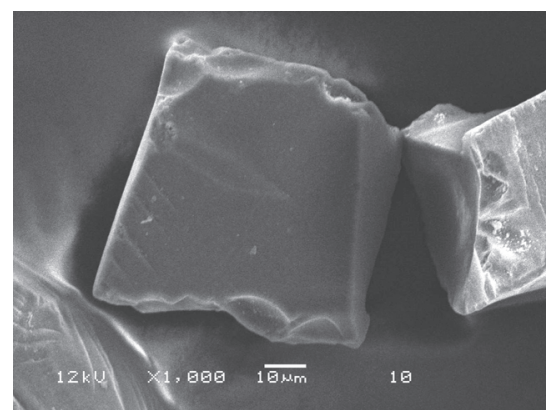

(j)

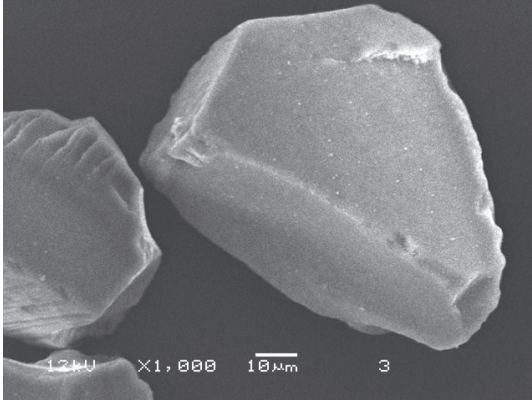

(c)

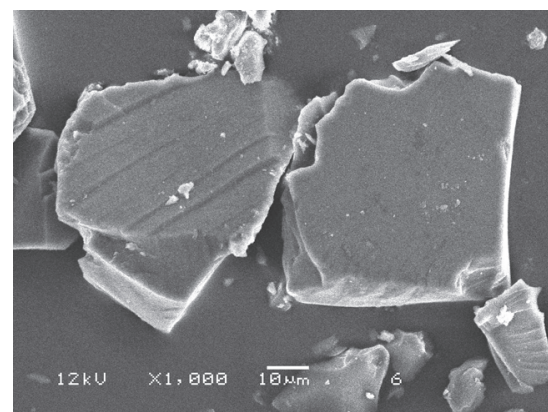

(f)

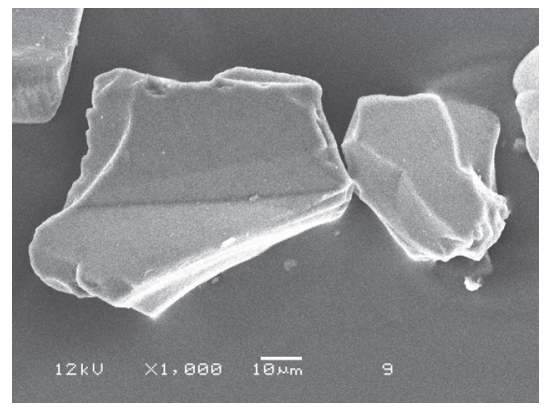

(i)

Figure 3: SEM image of (a) $\mathrm{SiO}_{2}$, (b) $\mathrm{SiO}_{2} @$ imineSA, (c) $\mathrm{SiO}_{2} @$ imineSA-Pd-II, (d) $\mathrm{SiO}_{2} @ \mathrm{imineSB}$ (e) $\mathrm{SiO}_{2} @ \mathrm{imineSB}-\mathrm{Pd}-\mathrm{II}$, and (f) SiO $\mathrm{S}_{2} @$

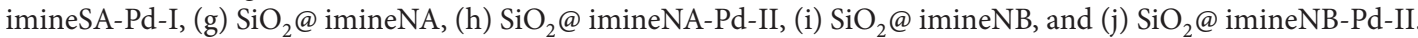

3.2. Catalytic Hydroamination. After structural characterization of the prepared $\mathrm{Pd}(\mathrm{II})$ immobilized on Salenfunctionalized silica, $\mathrm{SiO}_{2} @$ imineSA-Pd-II, $\mathrm{SiO}_{2} @$ imineSAPd-I, SiO $2 @$ imineSB-Pd-II, SiO $2 @$ imineNA-Pd-II, and
$\mathrm{SiO}_{2} @$ imineNB-Pd-II, its catalytic activity was investigated via the hydroamination of allene (1). The starting material was prepared as previously described. The reaction between the allene (1) and the aniline (2a) was selected as the model 


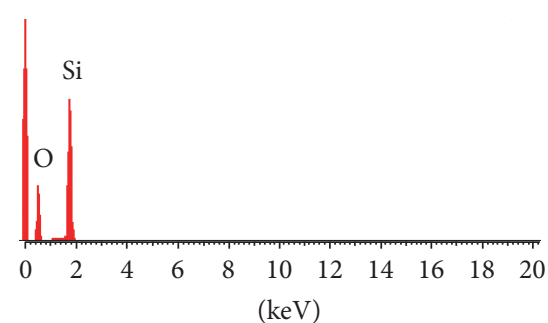

Full scale 9092 cts Cursor: $0.000 \mathrm{keV}$

(a)

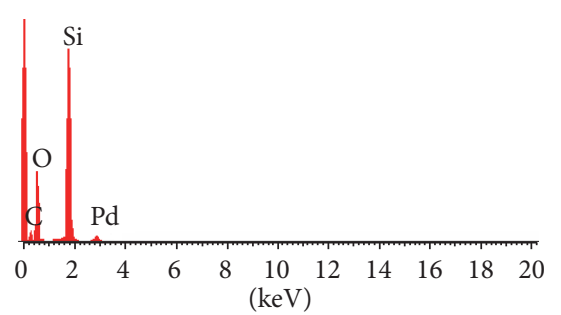

Full scale 2789 cts Cursor: $14.357 \mathrm{keV}$ (1 cts)

(d)

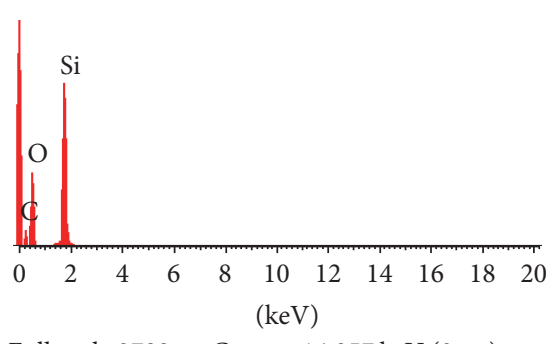

Full scale 2789 cts Cursor: $14.357 \mathrm{keV}$ ( 0 cts)

(g)

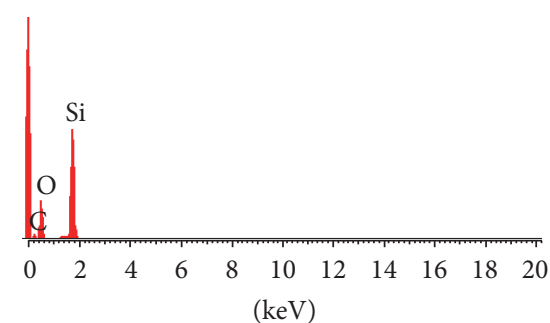

Full scale 9092 cts Cursor: $0.000 \mathrm{keV}$

(b)

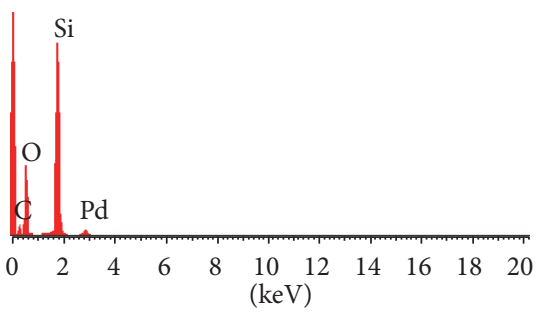

Full scale 2789 cts Cursor: $14.357 \mathrm{keV}$ (1 cts)

(e)

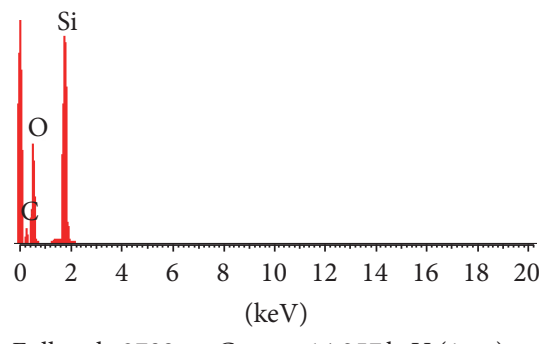

Full scale 2789 cts Cursor: $14.357 \mathrm{keV}$ ( 1 cts)

(h)

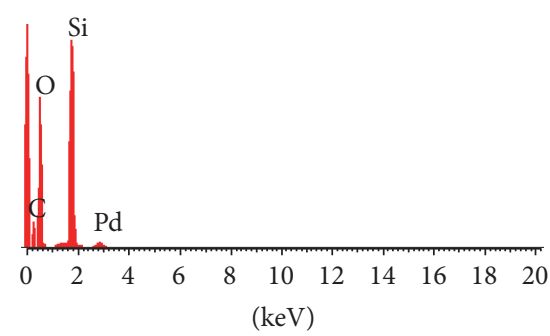

Full scale 2789 cts Cursor: $14.357 \mathrm{keV}$ (1 cts)

(j)

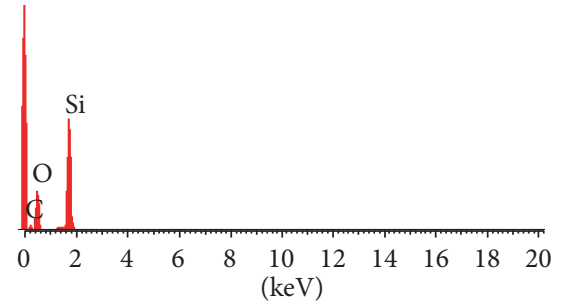

Full scale 9092 cts Cursor: $0.000 \mathrm{keV}$

(c)

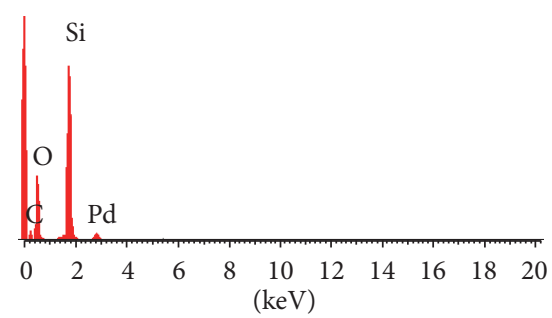

Full scale 2789 cts Cursor: $14.357 \mathrm{keV}$ (0 cts)

(f)

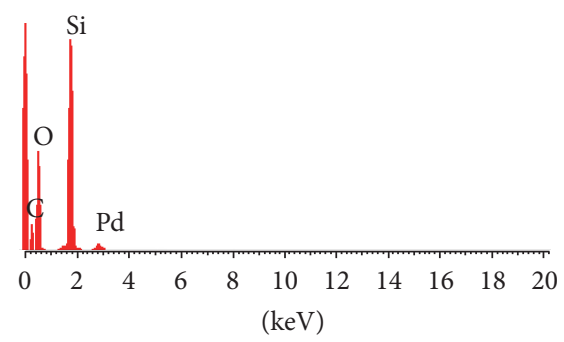

Full scale 2789 cts Cursor: $14.357 \mathrm{keV}$ ( 1 cts)

(i)

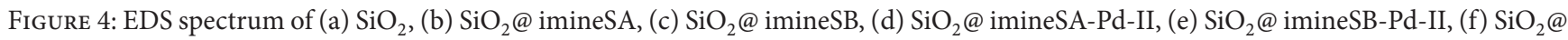
imineSA-Pd-I, (g) $\mathrm{SiO}_{2} @$ imineNA, (h) $\mathrm{SiO}_{2} @$ imineNB, (i) $\mathrm{SiO}_{2} @$ imineNA-Pd-II, and (j) $\mathrm{SiO}_{2} @$ imineNB-Pd-II.

reaction using THF as the solvent and TFA as the additive with $5 \mathrm{~mol} \%$ palladium catalyst, as shown in Table 2.

The reaction was successfully operated at room temperature under air without any special precautions. To verify the effect of the imine-functionalization on the catalysis, $\mathrm{SiO}_{2} @$ imineSA-Pd-II, $\mathrm{SiO}_{2} @$ imineSA-Pd-I, $\mathrm{SiO}_{2} @$ imineSB-Pd-II,
$\mathrm{SiO}_{2} @$ imineNA-Pd-II, $\mathrm{SiO}_{2} @$ imineNB-Pd-II, and homogeneous $\left[\mathrm{Pd}\left(\mathrm{OAc}_{2}\right)\right]$ were compared as catalysts (with the same palladium content) under identical conditions. It is necessary to note that $\mathrm{SiO}_{2} @$ imineSA-Pd-I exhibited the same yield as indicated by the homogeneous $\left[\mathrm{Pd}\left(\mathrm{OAc}_{2}\right)\right]$ (entries 1 and 3, Table 2). Then, when comparing with 
TABLE 1: Surface area, total pore volume, pore size distribution, and amount of Pd loaded on the surface of the silica-based materials.

\begin{tabular}{|c|c|c|c|c|c|}
\hline Entry & Materials & $S_{\mathrm{BET}}{ }^{\mathrm{a}}\left(\mathrm{m}^{2} \mathrm{~g}^{-1}\right)$ & Total pore volume $\mathrm{e}^{\mathrm{b}}\left(\mathrm{cm}^{3} \mathrm{~g}^{-1}\right)$ & Mean pore diameter ${ }^{\mathrm{c}}(\mathrm{nm})$ & $\mathrm{Pd}_{\text {content }}{ }^{\mathrm{d}} \pm \mathrm{SD}^{\mathrm{e}}\left(\mathrm{mg} \mathrm{g}^{-1}\right)$ \\
\hline 1 & $\mathrm{SiO}_{2}$ & 411.16 & 0.860 & 4.18 & $N A^{\mathrm{f}}$ \\
\hline 2 & $\mathrm{SiO}_{2} @$ imineSA & 340.58 & 0.503 & 2.95 & $N A^{f}$ \\
\hline 3 & $\mathrm{SiO}_{2} @$ imineSB & 366.92 & 0.589 & 3.21 & $N A^{f}$ \\
\hline 4 & $\mathrm{SiO}_{2} @$ imineNA & 273.49 & 0.430 & 3.14 & $\mathrm{NA}^{\mathrm{f}}$ \\
\hline 5 & $\mathrm{SiO}_{2} @$ imineNB & 268.89 & 0.416 & 3.10 & $N A^{f}$ \\
\hline 6 & $\mathrm{SiO}_{2} @$ imineSA-Pd-II & 358.63 & 0.505 & 2.82 & $30.74 \pm 0.42$ \\
\hline 7 & $\mathrm{SiO}_{2} @$ imineSA-Pd-I & 302.64 & 0.429 & 2.83 & $33.6 \pm 1.52$ \\
\hline 8 & $\mathrm{SiO}_{2} @$ imineSB-Pd-II & 365.38 & 0.539 & 2.95 & $29.58 \pm 1.63$ \\
\hline 9 & $\mathrm{SiO}_{2} @$ imineNA-Pd-II & 322.64 & 0.416 & 2.58 & $25.85 \pm 0.72$ \\
\hline 10 & $\mathrm{SiO}_{2} @$ imineNB-Pd-II & 305.41 & 0.407 & 2.65 & $25.12 \pm 0.77$ \\
\hline
\end{tabular}

${ }^{\mathrm{a}}$ BET method used in $\mathrm{N}_{2}$ sorption. ${ }^{\mathrm{b}}$ Single-point pore volume at $P / P_{o}=0.975 .{ }^{\mathrm{c}}$ Adsorption average pore diameter by BET method. ${ }^{\mathrm{d}}$ Determined by ICP-OES analysis. ${ }^{\mathrm{e}}$ Average of triplicates $\pm \mathrm{SD} .{ }^{\mathrm{f}}$ Not applicable.

TABLE 2: Optimization of reaction conditions of $C$-(tetra- $O$-acetyl- $\beta$-D-galactopyranosyl)allene (1) with aniline (2a).

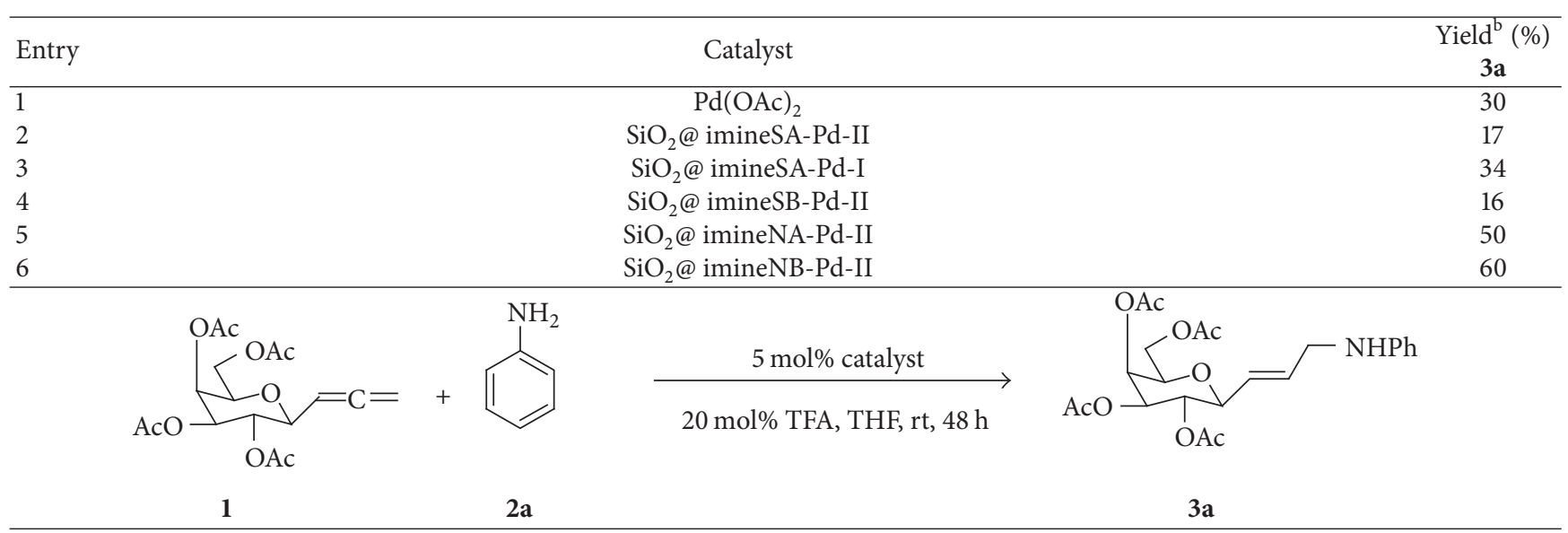

${ }^{a}$ All reactions were carried out with conditions: $C$-(tetra- $O$-acetyl- $\beta$-D-galactopyranosyl)allene (1) $(0.27 \mathrm{mmol})$ and aniline $(0.81 \mathrm{mmol})$ in $0.5 \mathrm{~mL}$ of solvent for $48 \mathrm{~h}$. ${ }^{\mathrm{b}}$ Isolated yields.

the imine-functionalization of silica from salicylaldehyde, the activity was significantly decreased with imineSA-PdII and $\mathrm{SiO}_{2} @$ imineSB-Pd-II (entries 2 and 4, Table 2). However, in the presence of the imine-functionalization of silica from 3-hydroxy-2-naphthaldehyde, SiO $@$ @ imineNAPd-II, and $\mathrm{SiO}_{2} @$ imineNB-Pd-II, the reaction proceeded with an improved yield of the desired product (3a) (entries 5 and 6 , Table 2). In addition, the formation of diallylated acetate and diallylated amine was not observed as minor products. The recycling ability of $\mathrm{SiO}_{2} @$ imineNB-Pd-II for the hydroamination of $\mathbf{1}$ with aniline was evaluated. After the recovery of the catalyst, it was reused directly without further purification. The catalyst could be successfully recycled for five consecutive cycles for the hydroamination of $\mathbf{1}$ with aniline and no significant loss of catalytic activity was observed after the fifth cycle. Additionally, palladium leaching in $\mathrm{SiO}_{2} @$ imineNB-Pd-II was determined. The palladium content of the clear filtrates obtained upon filtration after the reaction was $<0.2 \mathrm{ppm}$, from ICP-OES analyses.

To test the extent and restrictions of our catalyst, $\mathrm{SiO}_{2} @$ imineNB-Pd-II, we also studied the hydroamination of $\mathbf{1}$ with substituted anilines (2b-i) bearing an electron-poor or an electron-rich group on the benzene ring provided to the corresponding allylamines (3b-i) (Table 3 ).

According to previous reports, the results also showed that the onset potential for the heterogeneous catalyst was more positive than under the homogenous condition. This could be due to the reduced formation of diallylated amine and diallylated acetate as byproducts. 
TABle 3: Hydroamination of $C$-(tetra- $O$-acetyl- $\beta$-D-galactopyranosyl)allene (1) with aromatic amines ${ }^{\mathrm{a}}$.

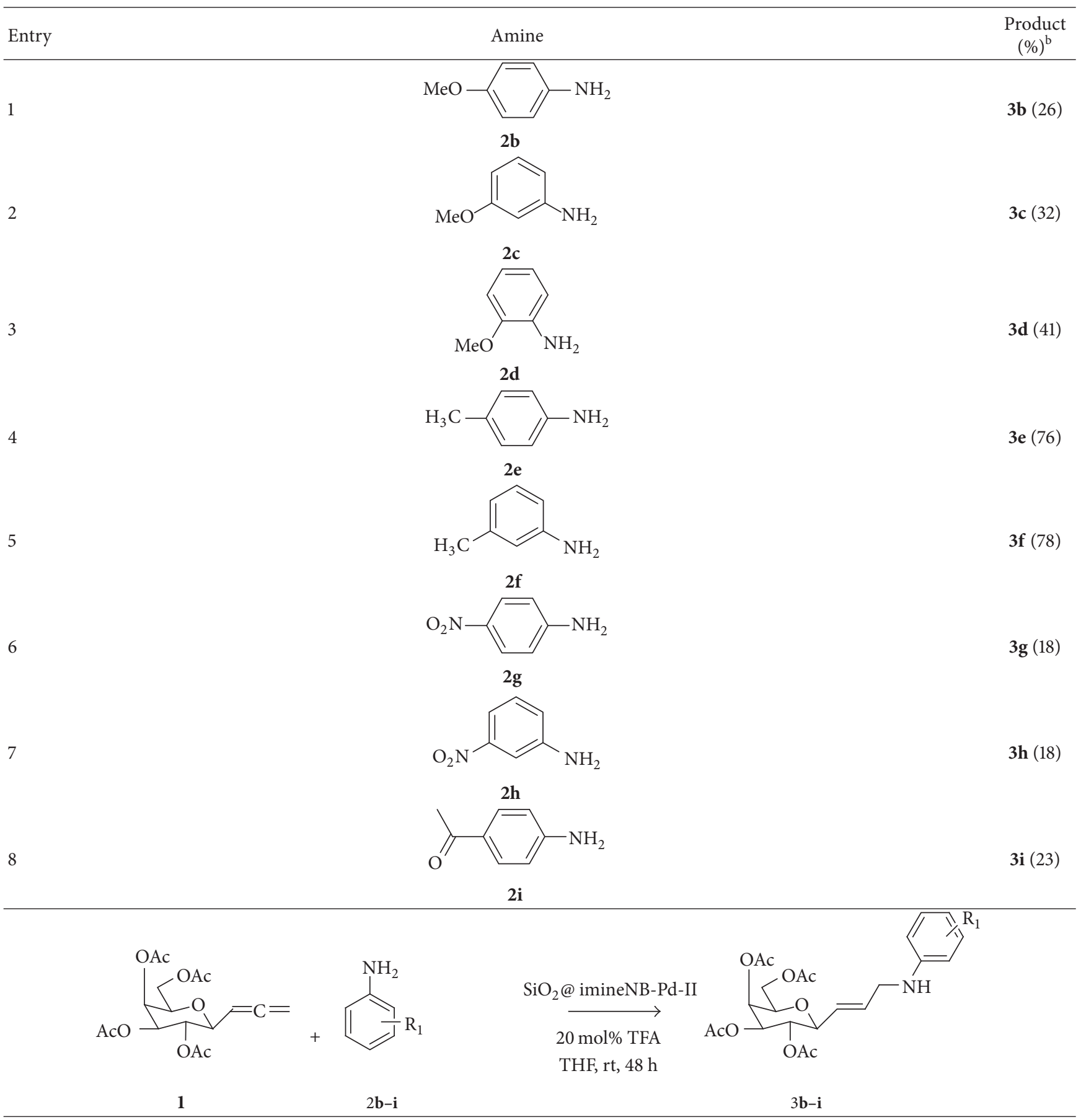

${ }^{a}$ Reaction condition: $C$-(tetra- $O$-acetyl- $\beta$-D-galactopyranosyl)allene (1) $(0.27 \mathrm{mmole})$ and aniline (0.81 mmole) in $0.5 \mathrm{~mL}$ of solvent for $48 \mathrm{~h}$; $\mathrm{SiO}_{2} @$ imineNB-

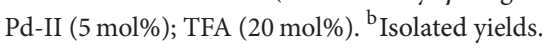

\section{Conclusion}

A novel mesoporous silica supported palladium(II)-based heterogeneous catalyst has been successfully synthesized by immobilizing $\mathrm{Pd}(\mathrm{OAc})_{2}$ onto a Salen-functionalized silica gel via coordination. The supported catalyst exhibited good activity for the hydroamination of allene (1) with a variety of aromatic amines. It could be easily recovered by simple separation even after the catalyst was reused for a fifth cycle with no significant loss of catalytic activity.

\section{Conflicts of Interest}

The authors declare that they have no conflicts of interest. 

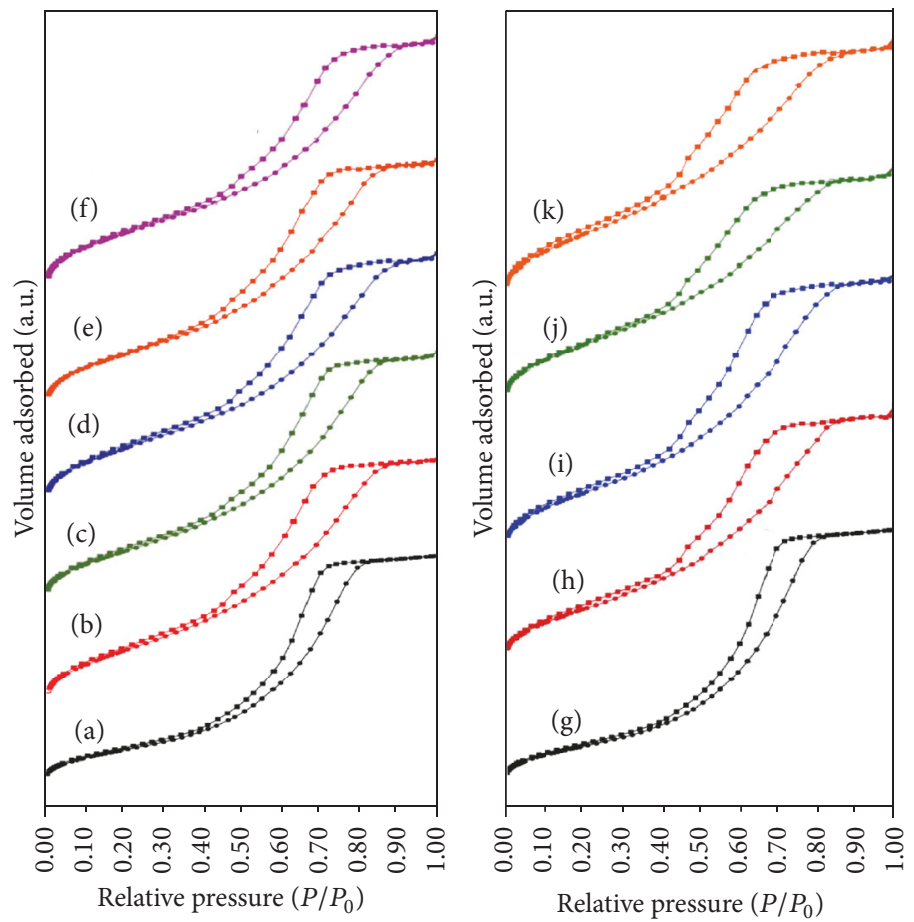

FIgURE 5: $\mathrm{N}_{2}$ adsorption-desorption isotherms of the silica-based materials: (a) $\mathrm{SiO}_{2}$, (b) $\mathrm{SiO}_{2} @ \mathrm{imineSA}$ (c) $\mathrm{SiO}_{2} @ \mathrm{imineSB}$ (d) SiO $@$

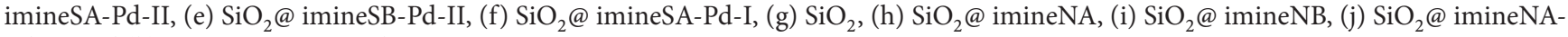
Pd-II, and (k) $\mathrm{SiO}_{2} @$ imineNB-Pd-II.

\section{Acknowledgments}

This work was supported by Mahasarakham University, Human Resource Development in Science Project (Science Achievement Scholarship of Thailand (SAST)), the Center of Excellence for Innovation in Chemistry (PERCH-CIC).

\section{References}

[1] L. Costantino and D. Barlocco, "Privileged structures as leads in medicinal chemistry," Current Medicinal Chemistry, vol. 13, no. 1, pp. 65-85, 2006.

[2] C. D. Duarte, E. J. Barreiro, and C. A. M. Fraga, "Privileged structures: A useful concept for the rational design of new lead drug candidates," Mini-Reviews in Medicinal Chemistry, vol. 7, no. 11, pp. 1108-1119, 2007.

[3] T. E. Müller and M. Beller, "Metal-initiated amination of alkenes and alkynes," Chemical Reviews, vol. 98, no. 2, pp. 675-703, 1998.

[4] P. W. Roesky and T. E. Müller, "Enantioselective catalytic hydroamination of alkenes," Angewandte Chemie - International Edition, vol. 42, no. 24, pp. 2708-2710, 2003.

[5] F. Alonso, I. P. Beletskaya, and M. Yus, "Transition-metalcatalyzed addition of heteroatom-hydrogen bonds to alkynes," Chemical Reviews, vol. 104, no. 6, pp. 3079-3159, 2004.

[6] M. Kawatsura and J. F. Hartwig, "Palladium-catalyzed intermolecular hydroamination of vinylarenes using arylamines," Journal of the American Chemical Society, vol. 122, no. 39, pp. 9546-9547, 2000.

[7] L. Huang, M. Arndt, K. Gooßen, L. J. Gooßen, and H. Heydt, "Late transition metal-catalyzed hydroamination and hydroamidation," Chemical Reviews, vol. 115, no. 7, pp. 25962697, 2015.

[8] K. M. Brummond and J. E. DeForrest, "Synthesizing allenes today," Synthesis, no. 6, pp. 795-818, 2007.

[9] P. J. Walsh, A. M. Baranger, and R. G. Bergman, "Stoichiometric and catalytic hydroamination of alkynes and allene by zirconium bisamides Cp2Zr(NHR)2," Journal of the American Chemical Society, vol. 114, no. 5, pp. 1708-1719, 1992.

[10] J. S. Johnson and R. G. Bergman, "Imidotitanium complexes as hydroamination catalysts: Substantially enhanced reactivity from an unexpected cyclopentadienide/amide ligand exchange," Journal of the American Chemical Society, vol. 123, no. 12, pp. 2923-2924, 2001.

[11] R. O. Ayinla and L. L. Schafer, "Bis(amidate) titanium precatalyst for the intermolecular hydroamination of allenes," Inorganica Chimica Acta, vol. 359, no. 9, pp. 3097-3102, 2006.

[12] L. Besson, J. Goré, and B. Cazes, "Palladium-catalyzed addition of malonate type compounds to allenes via a hydropalladation process," Tetrahedron Letters, vol. 36, no. 22, pp. 3853-3856, 1995.

[13] M. Al-Masum, M. Meguro, and Y. Yamamoto, "The two component palladium catalyst system for intermolecular hydroamination of allenes," Tetrahedron Letters, vol. 38, no. 34, pp. 60716074, 1997.

[14] J. Zhang, C.-G. Yang, and C. He, "Gold(I)-catalyzed intra- and intermolecular hydroamination of unactivated olefins," Journal of the American Chemical Society, vol. 128, no. 6, pp. 1798-1799, 2006.

[15] C. Khamwong and U. Sakee, "Palladium-catalyzed hydroamination of C-(tetra-O-acetyl- $\beta$-d-galactopyranosyl)allene," Carbohydrate Research, vol. 346, no. 2, pp. 334-339, 2011. 
[16] C. Khamwong, S. Kruanetr, and U. Sakee, "Gold(III)-catalyzed intermolecular hydroamination of $c$-(tetra-O-acetyl- $\beta$-Dgalactopyranosyl)allene," Letters in Organic Chemistry, vol. 9, no. 9, pp. 650-654, 2012.

[17] N. Selander and K. J. Szabó, “Catalysis by palladium pincer complexes," Chemical Reviews, vol. 111, no. 3, pp. 2048-2076, 2011.

[18] L. Yin and J. Liebscher, "Carbon-carbon coupling reactions catalyzed by heterogeneous palladium catalysts," Chemical Reviews, vol. 107, no. 1, pp. 133-173, 2007.

[19] A. Corma, "From microporous to mesoporous molecular sieve materials and their use in catalysis," Chemical Reviews, vol. 97, no. 6, pp. 2373-2419, 1997.

[20] N. Linares, A. E. Sepúlveda, J. R. Berenguer, E. Lalinde, and J. Garcia-Martinez, "Mesoporous organosilicas with Pd(II) complexes in their framework," Microporous and Mesoporous Materials, vol. 158, pp. 300-308, 2012.

[21] M. Čapka, M. Czakoová, E. Hillerová, E. Paetzold, and G. Oehme, "[2-(3-Trimethoxysilylthio)ethyl]diphenylphosphinea new agent for transition metal immobilization," Journal of Molecular Catalysis A: Chemical, vol. 104, no. 2, pp. 123-125, 1995.

[22] A. Ghorbani-Choghamarani, F. Nikpour, F. Ghorbani, and F. Havasi, "Anchoring of Pd(ii) complex in functionalized MCM41 as an efficient and recoverable novel nano catalyst in C-C, C$\mathrm{O}$ and $\mathrm{C}-\mathrm{N}$ coupling reactions using $\mathrm{Ph}_{3} \mathrm{SnCl}$," RSC Advances, vol. 5, no. 42, pp. 33212-33220, 2015.

[23] M. Opanasenko, P. Štěpnička, and J. Čejka, "Heterogeneous Pd catalysts supported on silica matrices," RSC Advances, vol. 4, no. 110, pp. 65137-65162, 2014.

[24] Y. He and C. Cai, "Polymer-supported macrocyclic Schiff base palladium complex: an efficient and reusable catalyst for Suzuki cross-coupling reaction under ambient condition," Catalysis Communications, vol. 12, no. 7, pp. 678-683, 2011.

[25] Y.-H. Zhu and P. Vogel, "Synthesis of a C-disaccharide analog of the Thomsen-Friedenreich (T) epitope," Synlett, no. 1, pp. 79-81, 2001.

[26] L. Kröger, D. Henkensmeier, A. Schäfer, and J. Thiem, "Novel O-glycosyl amino acid mimetics as building blocks for Oglycopeptides act as inhibitors of galactosidases," Bioorganic and Medicinal Chemistry Letters, vol. 14, no. 1, pp. 73-75, 2004. 

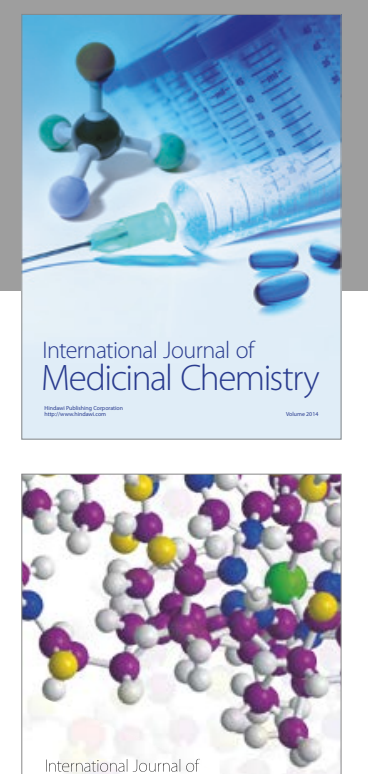

Carbohydrate Chemistry

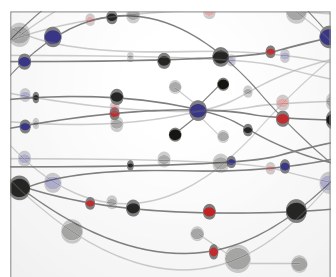

The Scientific World Journal
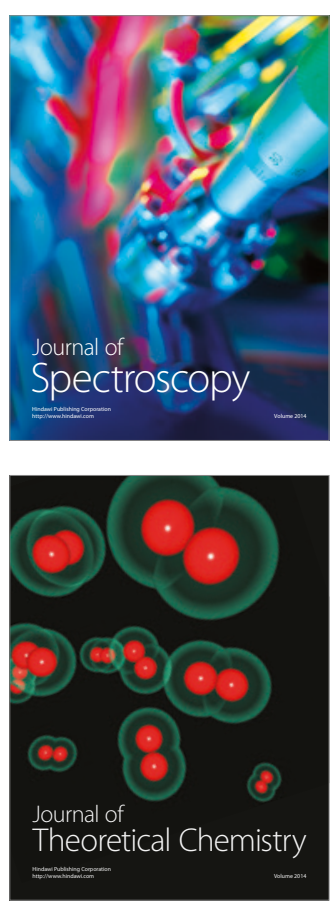
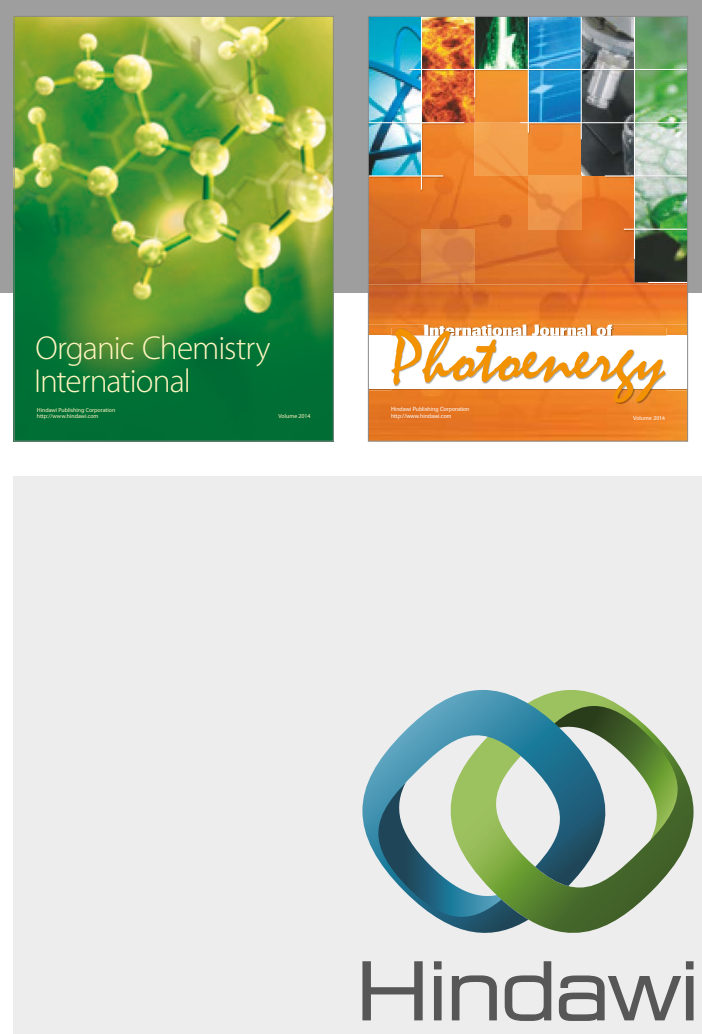

Submit your manuscripts at

https://www.hindawi.com

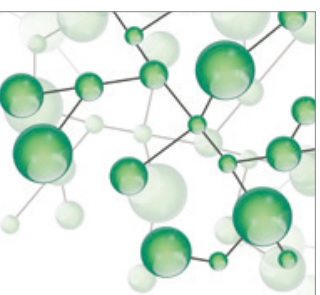

International Journal of

Inorganic Chemistry

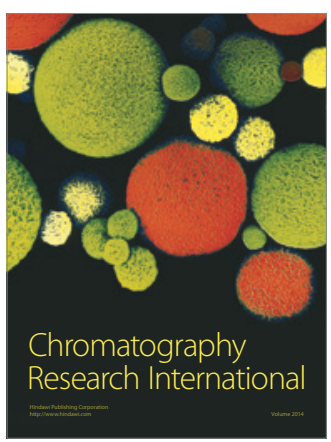

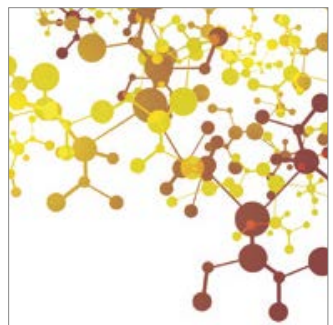

Applied Chemistry
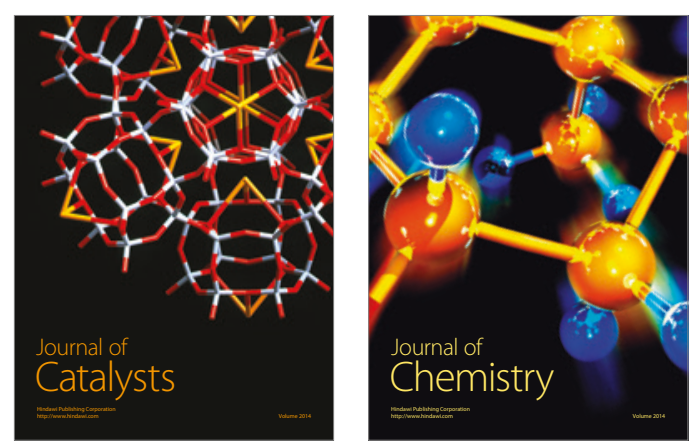
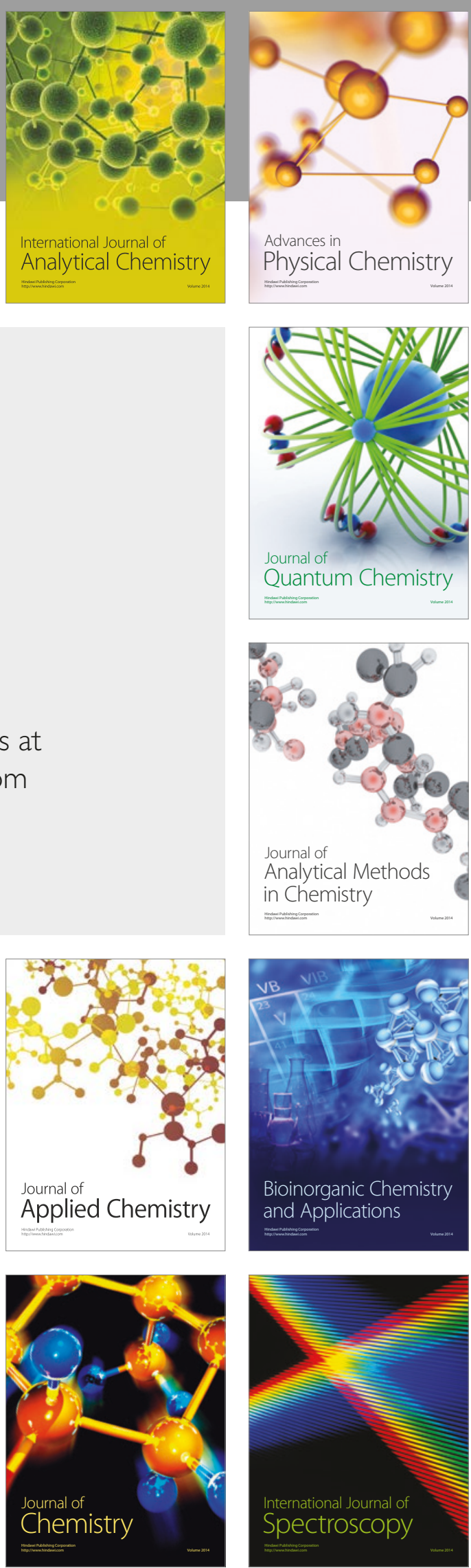